\title{
sFLT01 modulates invasion and metastasis in prostate cancer DU145 cells by inhibition of VEGF/GRP78/MMP2\&9 axis
}

\author{
Sepideh Taghizadeh ${ }^{1}$, Zahra-Soheila Soheili ${ }^{1 *}$, Mehdi Sadeghi ${ }^{1}$, Shahram Samiei², Ehsan Ranaei Pirmardan³, \\ Ali Kashanian ${ }^{1}$, Fahimeh Zakeri ${ }^{1}$, Hamid Latifi-Navid ${ }^{1}$ and Hoda Shams Najafabadi ${ }^{1}$
}

\begin{abstract}
Background: About $90 \%$ of cancer-related deaths are due to metastasis of cancer cells, and angiogenesis is a critical step in this process. sFLT01 is a novel fusion protein and a dual-targeting agent that neutralizes both VEGF and PIGF proangiogenic activities. GRP78 dual effect in tumor growth and angiogenesis could be activated under VEGF stimulation. The current study was designed to investigate the inhibitory impact of sFLT01 protein on VEGF/ GRP78 axis. To this point, sFLT01 construct was synthesized, recombinant plasmid was expressed in eukaryotic host cells, sFLT01-HisTag protein was extracted and analyzed. The functional activity of sFLT01 on VEGF-enhanced tube formation and angiogenesis of HUVEC cells were examined. Eventually, the inhibitory impact of sFLT01 on growth, invasiveness, and migration of human prostate cancer cell line, DU145, was assessed. Real-time PCR evaluated the level of GRP78 and its effect on the downstream factors; matrix metallopeptidase proteins 2\&9 (MMP2\&9) along with tissue inhibitor of metalloproteinase proteins1\&2 (TIMP1\&2) under SFLT01 stimulation.
\end{abstract}

Results: According to the data, sFLT01 protein showed modulatory impact on proliferation, invasion, and migration of DU145 cells along with the potential of HUVECs angiogenesis. Real-Time PCR analysis depicted a significant downregulation in GRP78, MMP2 and MMP9 transcripts' levels, and a subsequent elevation of TIMP1 and TIMP2 expression under sFLT01 stimulation was detected.

Conclusion: Overall, these data indicated that the inhibitory impact of sFLT01 on cancer cells growth and invasiveness could be mediated through the modulation of VEGF/GRP78/MMP2\&9 axis and activation of TIMPs.

Keywords: Prostate cancer, Angiogenesis, sFLT01, VEGF, GRP78

\section{Background}

Prostate cancer (PC) is a malignant growth of prostate cells with little symptoms and ranked as the second deadliest cancer worldwide. According to the cancer statistics, over 6000 new PC cases have been diagnosed each year in the united states of America [1]. Although the PC population in Asian countries is still low, the

\footnotetext{
* Correspondence: soheili@nigeb.ac.ir

'Department of Molecular Medicine, National Institute of Genetic Engineering and Biotechnology, 14965/161, Tehran, Iran

Full list of author information is available at the end of the article
}

incidence rate of $\mathrm{PC}$ has been reported to increase faster than the USA and European countries due to the lifestyle alteration [2].

About $90 \%$ of cancer-related deaths are due to metastasis of cancer cells from the primary tumor to other organs [3]. PC is the most common non-skin malignancy among men, and since the advent of PSA testing, most patients have been diagnosed with topical PC and chemotherapy-treated with Docetaxel and Prednisone drugs $[4,5]$. However, not all of the patients are fully

C C The Author(s). 2021 Open Access This article is licensed under a Creative Commons Attribution 4.0 International License, which permits use, sharing, adaptation, distribution and reproduction in any medium or format, as long as you give appropriate credit to the original author(s) and the source, provide a link to the Creative Commons licence, and indicate if changes were made. The images or other third party material in this article are included in the article's Creative Commons licence, unless indicated otherwise in a credit line to the material. If material is not included in the article's Creative Commons licence and your intended use is not permitted by statutory regulation or exceeds the permitted use, you will need to obtain permission directly from the copyright holder. To view a copy of this licence, visit http://creativecommons.org/licenses/by/4.0/ The Creative Commons Public Domain Dedication waiver (http://creativecommons.org/publicdomain/zero/1.0/) applies to the data made available in this article, unless otherwise stated in a credit line to the data. 
recovered. Hence, ongoing efforts are being made to design new therapeutic strategies for targeting the PC.

Angiogenesis is a critical step in cancer metastasis and could be stimulated by various factors, including the vascular endothelial growth factor (VEGF). During the angiogenesis, extracellular membrane of the body vessels is degraded quickly, and new capillaries emerge by the enhanced level of highly activated endothelial cells. Up today, multiple intra and extracellular signaling factors have been introduced that are playing important roles in tumor angiogenesis.

Among them, VEGF is reported to be directly associated with cancer cells proliferation, metastasis, angiogenesis, and chemotherapy resistance in various human cancers [6]. Anti-VEGF agents that neutralize VEGF in some animal model describe inhibitory effects on proliferation and metastatic dissemination in solid tumors [7]. In cancerous tumors, GRP78 expression could be provoked due to the hypoxia increased glucose demand or glycolytic activity and this, supplies the cells with glucose and oxygen [8]. This heat-shock protein is located in the endoplasmic reticulum (ER) lumen and regulates protein folding and transportation along with ER homeostasis and responses to stress signals such as accumulation of unfolded proteins $[9,10]$.

Glucose-regulated protein 78 (GRP78) is reported to be associated with angiogenesis and metastasis of cancer tumors directly. Knockdown of GRP78 suppresses VEGF- signaling and endothelial cell proliferation. Yet, VEGF induces expression of cell surface GRP78 in endothelial cells [11]. MMPs or matrix metalloproteinases are a group of zinc-binding proteins that involve in the degradation of ECM components, the tumor surface and the basement membrane, which causes tumor cell migration into other tissue. MMPs along with EMT play key role to promote angiogenesis and metastasis [12]. The positive impact of GRP78 on MMP2 expression has been previously described in hepatocyte carcinoma cells, in which GRP78 knocking down, reduced the MMP2 level and activity via ERK/JNK signaling pathway suppression [13]. Also, it has been shown that the ERK signaling pathway stimulates MMP2 and MMP9 activity though triggering the ADAM17, a metalloprotease enzyme highly expressed in various human disorders, including cancers [14].

Accordingly, most of the chemotherapies in patients with advanced cancer are based on using angiogenesis inhibitors such as Bevacizumab, Thalidomide, and its analogs, kinase inhibitors like Sorafenib and Cediranib (AZD2171), and other angiogenic signaling repressors [15].

It has been reported that PC cells widely express VEGF protein, and the sera level of VEGF in patients with metastatic $\mathrm{PC}$ is higher than in patients with early PC [16]. Therefore, neutralizing VEGF may be considered as a promising strategy for angiogenesis inhibition. One of the VEGF blockers is sFLT01; a secreted chimeric protein consists of an FMS-like tyrosine kinase (FLT) domain of VEGFR1, the Glycine linker, and an Fc domain of IgG1 [17]. sFLT01 acts as a soluble receptor and inhibits angiogenesis by blocking the VEGF protein along with increasing the endothelial cell attachment to the extracellular matrix. Moreover, this protein may also have acceptable safety profiles [18]. The strong antitumor effect of sFLT01 was demonstrated in several xenograft models. Intraperitoneal injection of vehicle or sFLT01 (10 or $25 \mathrm{mg} / \mathrm{kg}$ ) was performed twice per week in mice bearing SC H460 NSCLC, HT29 colon carcinoma, Karpas 299 lymphoma, or MOLM-13 AML tumors [17]. The current study was designed to investigate the anticancer effects of sFLT01 protein on the proliferation and invasiveness of the PC cell line.

\section{Statistical analysis}

All statistical analyses were performed with IBM SPSS Statistics software version 22 (IBM, USA). Shapiro-Wilk normality test was used for data normalization. Significant statistical differences were calculated by one/twoway analyses of variance (ANOVA) and Tukey's multiple comparison tests. The data were depicted as the mean \pm SD (Standard deviation) and considered as significant if $P<0.05{ }^{(*)}$.

\section{Results}

Cloning, transfection, purification, and analysis of recombinant $\mathrm{sFLT01}$ protein

The final sFLT01-HisTag sequence (1116 bp) was inserted into a pAAV-MCS-GFP plasmid (5900 bp), and resulted in a pAAV-sFLT01-HisTag-GFP plasmid, $7 \mathrm{~kb}$ length (Fig. 1a). The recombinant plasmids were then amplified and examined with the EcoRI/BamHI enzymes.

After verification of gene cloning, the pAAV-sFLT01HisTag-GFP plasmid was transfected into the DU145 cells for sFLT01-HisTag production and analysis. DU145 cultures that had been treated with media and DU145 cultures that had been transfected by pAAV-MCS-GFP recruited as controls for the pAAV-MCS-sFLT01transfected cultures. $48 \mathrm{~h}$ after transfection, cells were examined for GFP expression and revealed that cells were positive for GFP (Fig. 1b).

To extract the sFLT01 protein for further analysis, CM from HEK293T cells, transfected with pAAV-sFLT01HisTag-GFP, was collected $72 \mathrm{~h}$ after transfection, purified with nickel affinity chromatography and determined using western blotting (Fig. 1c).

Impact of sFLT01 protein on prostate cancer cells viability Cellular viability was determined by analyzing the activity of mitochondrial succinate dehydrogenase enzyme. 


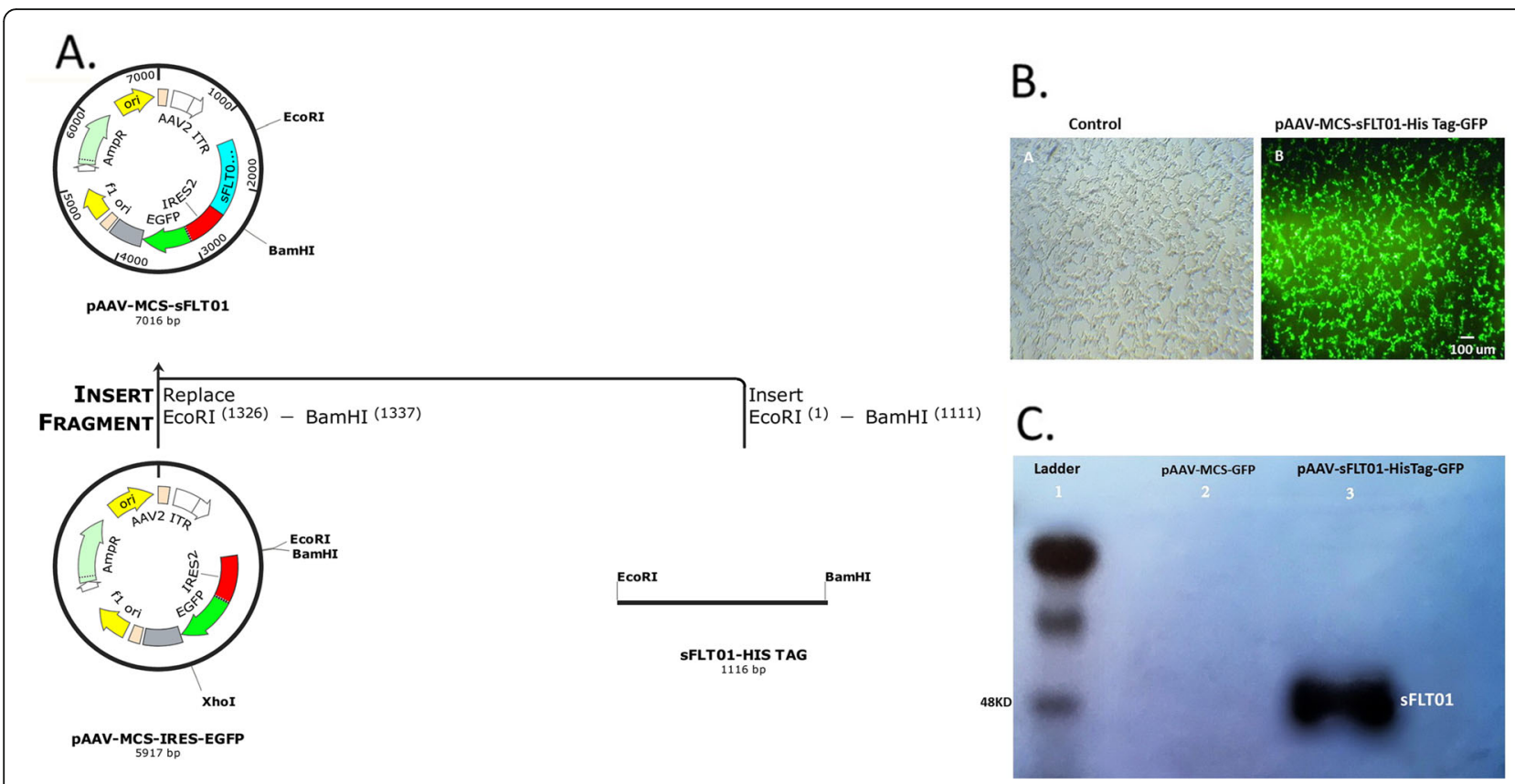

Fig. 1 Cloning of the SFLTO1, vector transfection and western blot analysis. a The polyhistidine-tag was added at the end of sFLT01 sequence, and cloned into pAAV-MCS-GFP plasmid. SFLT01-HisTag fragment digestion examined with the EcoRI and BamHI enzymes, resulted in $1116 \mathrm{bp}$ fragment (sFLT01-HisTag) indicating that the target sequence was inserted in the vector body. $\mathbf{b}$ Transfection of DU145 cells with the recombinant pAAV-sFLT01-HisTag-GFP plasmid showed more than 90\% of the cells were positive for GFP, (a): DU145 cells; no transfection, (b): GFP over expression in DU145 cells which had been transfected by pAAV-sFLT01-His Tag-GFP. c CM of HEK293T cells that had been transfected by PAAV-sFLT01-HisTag-GFP was collected $72 \mathrm{~h}$ post transfection, purified with nickel affinity chromatography column and applied in western blot experiment by the human VEGFR1/FIt-1 primary antibody

The target groups consisted of DU145 cells treated with various doses of CM collected from the DU145 cells $(10-200 \mu \mathrm{l} /$ well), and a control group of cancer cells incubated with RPMI1640 media. According to the data, cellular viability of the cancer cells treated with $100 \mu \mathrm{l}$ of $\mathrm{CM}$ was about 50\% lower than the control group $(P<0.05$, Fig. 2). This dose was chosen for future examinations.

\section{sFLT01 treatment reduced tube formation ability in HUVECS}

Considering this point that VEGF is a known angiogenesis factor and Matrigel develops an angiogenic natural response, the suppressive effect of sFLT01 protein on formation of capillary structures in HUVEC cells was examined (Fig. 3). According to the data, sFLT01 treatment significantly suppressed VEGF-enhanced tube formation, in a way that the number of master junctions in the sFLT01 CM group was 4.63 fold lower than control (treated by $\mathrm{CM}$ from pAAV-MCS-GFP transfected cells, $P<0.05)$. Similar result was obtained from analyzing the number of meshes between target and control groups; in which sFLT01 containing CM reduced meshes population about 6 fold in sFLT01 treated HUVECs versus control HUVEC cells $(P<0.05)$.
Impact of sFLT01 protein on invasiveness and migration of prostate cancer cells

Wound healing assay and cell invasion analysis were performed to estimate the impact of sFLT01 protein on the migration and invasiveness of PC cells. The data indicated that following the treatment with $\mathrm{CM}$ media containing sFLT01 protein for $24 \mathrm{~h}$ and $48 \mathrm{~h}$, the mobility of DU145 cells was significantly decreased versus the control group (treated by CM from pAAV-MCS-GFP CM transfected cells); 0.43 -fold $(P<0.05)$ and 2.27 -fold $(P<0.001)$, respectively (Fig. 4). Accordingly, the invasion of the cancer cells incubated by pAAV-sFLT01-HisTag-GFP transfected cells was statistically lower than the control group (1.34fold, $P<0.05$, Fig. 5). These observations showed that the sFLT01 protein imposed a negative impact on the invasiveness and migration of DU145 cells.

\section{Modulatory effect of sFLT01 protein on the expression of VEGF signaling mediators}

To investigate the impact of sFLT01 protein on VEGF expression in DU145 cells, the level of glucose-regulated protein 78 (GRP78), matrix metallopeptidase protein 2 \& 9 (MMP2\&9), and tissue inhibitor of metalloproteinase protein $1 \& 2$ (TIMP1\&2) were evaluated (Fig. 6). Real-time PCR data in DU145 cells transfected by pAAV-sFLT01-HisTag-GFP showed that expression of 


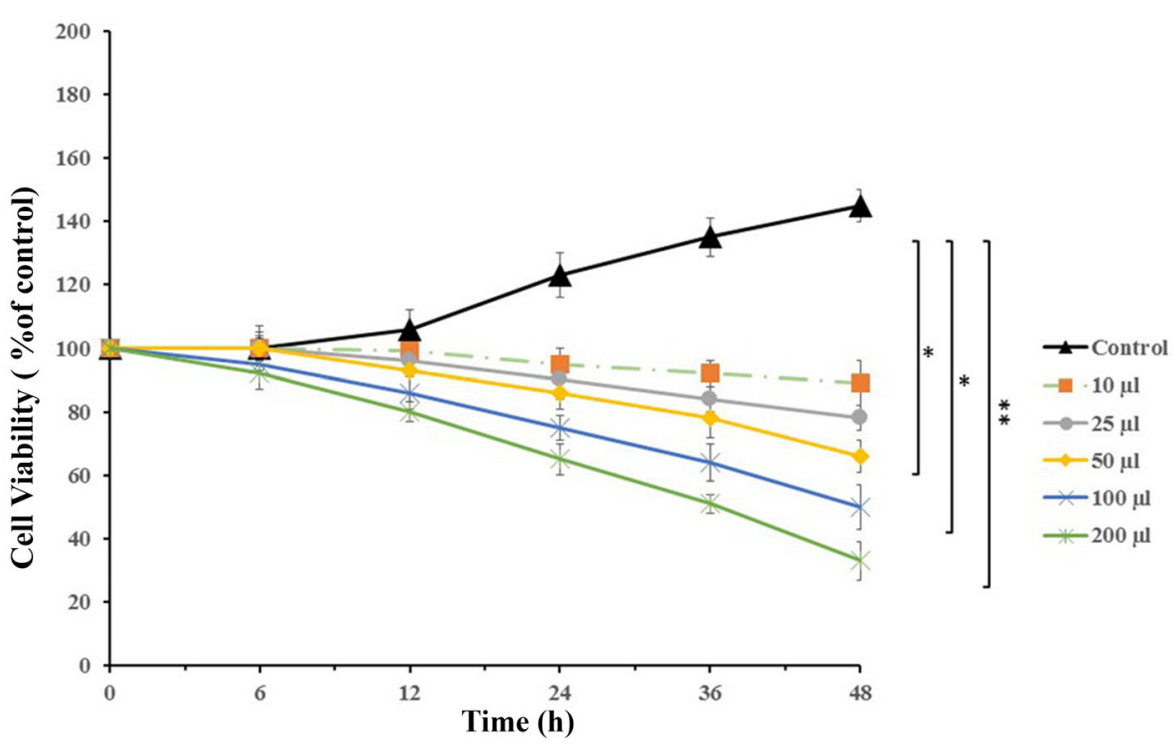

Fig. 2 Cell viability analysis. Prostate cancer DU145 cells were incubated with various doses of conditioned media containing sFLT01 protein for $48 \mathrm{~h}$. Cell density was analyzed using the MTT assay method and measured by a microplate reader at $580 \mathrm{~nm}$ wavelength. Cellular viability of the treated cells was $50 \%$ lower than the control group $(P<0.05)$

GRP78, MMP2, and MMP9 were downregulated about 17,40 , and $43 \%$, respectively when compared to control cultures that had been transfected by pAAV-MCS-GFP. However, upregulation was detected for TIMP1 (20\%) and TIMP2 (30\%), under sFLT01 stimulation.

\section{Discussion}

Tumor formation is a multi-step process including survival, proliferation, angiogenesis, migration, and invasion. It is regulated by multiple cell signaling pathways [19]. Since, angiogenesis is significantly regulated by VEGF, administration of anti-VEGF agents and VEGF inhibitors may offer a rational therapeutic approach in prostate cancer [20]. The primary finding in our study was the consequences of VEGF neutralization on tube formation and angiogenesis in HUVECs, our data showed that sFLT01 protein had robust anti-VEGF efficacy and inhibited capillary structures in in vitro angiogenesis examination. So, sFLT01 may play a key role in angiogenesis inhibition via VEGF neutralizing in endothelial cells. Proliferation dysregulation is one of the main characteristics of tumorigenesis. Data represented a strong correlation between the expression of sFLT01 and inhibition of DU145 cell proliferation. Other studies had previously shown that, sFLT01 was able to neutralize VEGF and block VEGF-stimulated HUVECs proliferation $[17,21]$ as well. HB-002.1 is a novel recombinant VEGF blocker with a significant dose-dependent inhibition on HUVECs proliferation and VEGF-induced tube formation when compared to that of bevacizumab function [22]. Another study reported that Bevacizumab inhibits the proliferation of A2780cis cells in ovarian cancer [23]. The AKT/ PI3K pathway and PTEN/PI3K signaling pathways regulate expression of VEGF and HIF- $1 \alpha$ in prostate cancer cell lines. These pathways may contribute to tumor angiogenesis in this cancer [24, 25]. MEK/ERK/ RAF activation pathway is associated with endothelial cell proliferation may also contribute to progression of angiogenesis and invasiveness in solid tumors [26].

The fundamental process that contributes to tumor cell invasion, metastasis and also one of the critical steps of angiogenesis is endothelial cell migration [27]. We showed that, inhibition of VEGF by sFLT01 lead to reduced migration and decreased invasiveness of metastatic prostate cancer cells. A previously reported study revealed that, Luteolin blocked VEGF induced endothelial cells migration and invasion of prostate cancer in a dose-dependent manner [28]. Bevacizumab along with other anti-VEGF therapy impairs tumor invasiveness in a xenograft model due to increased SFK signaling pathway [29]. In combination with Atezolizumab, it dramatically reduces migration and invasion of A2780cis ovarian cancer cell line as well [23]. Apatinib is a tyrosine kinase inhibitor that effectively blocks VEGFR2. It suppresses migration and invasion in QBC939 and TFK-1 cells in cholangiocarcinoma (CCA) through modulatory effects on AKT and ERK/MEK/RAF signaling pathways [30]. VEGF activates downstream pathways including VEGFR-2/PI3K/Akt-PKB axis in endothelial cells, it follows activation of the small GTPases of the 


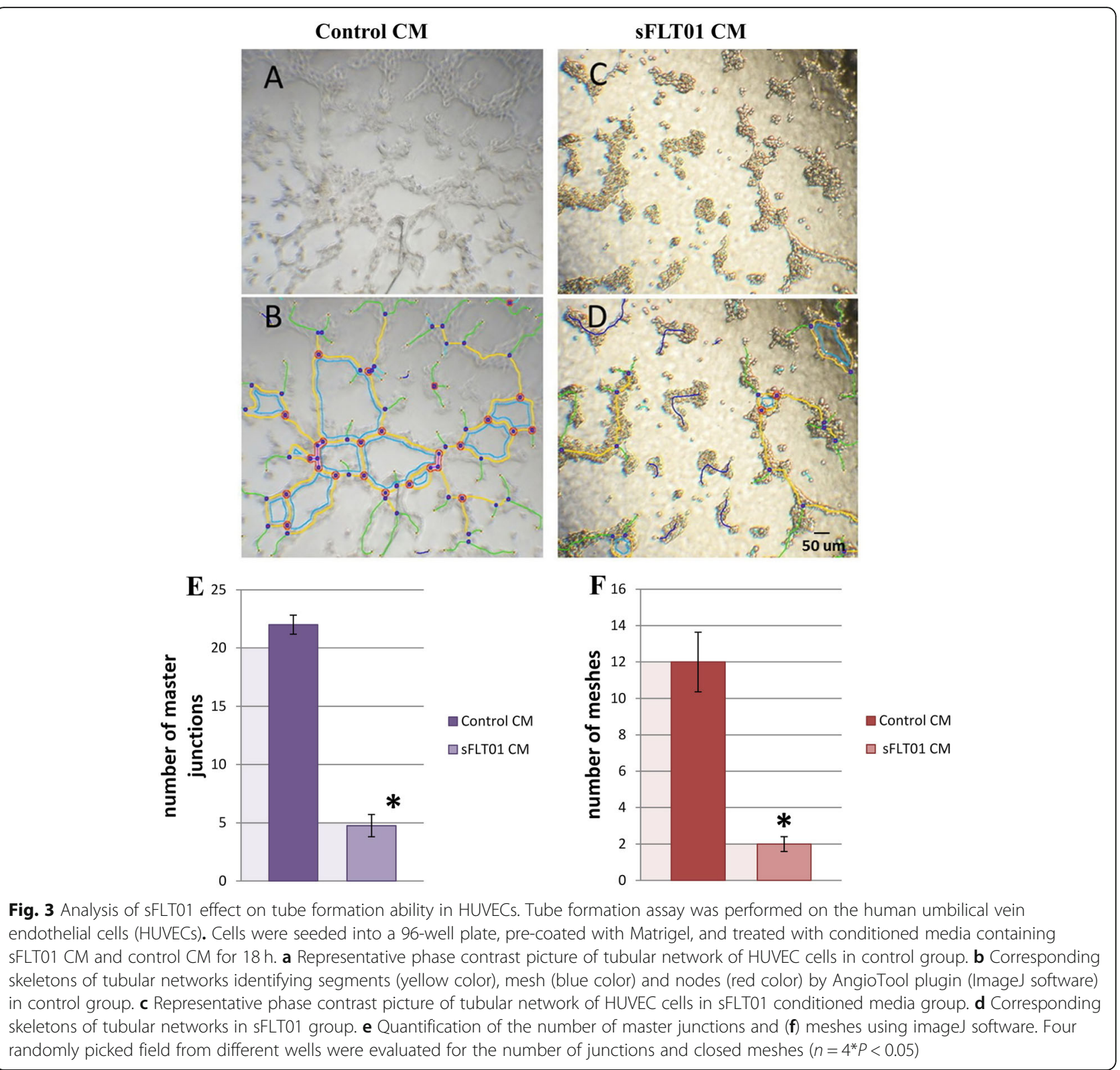

Rho family, PI3K and eNOS; SAPK2/p38; and phosphorylation of VEGFR-2 and FAK and then, endothelial cell migration occurs [31].

VEGF is one of the main inducers of GRP78 expression, which increases the proliferation ability of the vein endothelial cells [32]. Previous studies indicated that the growth, angiogenesis, and metastasis of cancer cells could be interrupted due to VEGF/GRP78 axis. GRP78 heterozygosity in transgenic-induced mice model of mammary tumors provokes apoptosis via increasing the CCAAT-enhancer-binding protein homologous protein (CHOP) expression and strong activation of procaspase7 [33]. Accordingly, the growth of B16 melanoma metastatic lesions in mice carrying $\mathrm{GRP}^{+/-}$was significantly slower than wild-type GRP78 hosts [34]. Meanwhile, GRP78 silencing in endothelial cells significantly decreased tumor angiogenesis and proliferation in immortalized endothelial cells without any negative impact on healthy cells population [34]. Analysis of pancreatic ductal adenocarcinoma (PDAC) patients indicated significant expression of GRP78. Subsequent knocking out of GRP78 in PDAC cell lines affected tumoral proliferation and invasiveness by modulation of CyclinD1, CDK4, and CDK6 along with RhoA, ROCK1, JAK2, vimentin, Smad4, and p-STAT3 proteins [35]. The oncoprotein STAT3 is shown to provoke the PDAC invasion via upregulation of the MMP enzyme family expression and activity [36, 37]. 

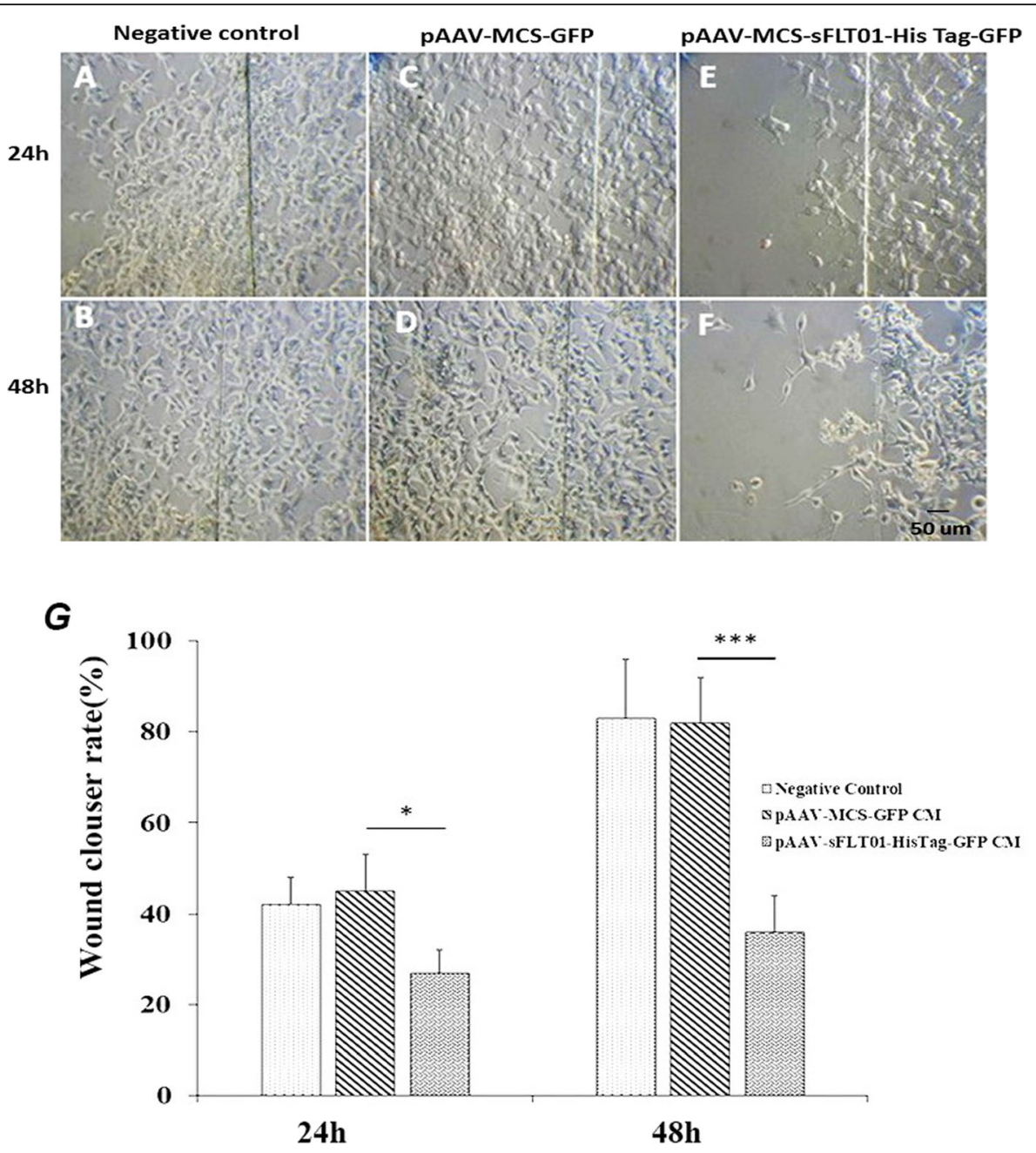

Fig. 4 Wound healing assay. Cells were treated with $100 \mu$ of conditioned media from DU145 cultures that had been transfected by sFLT01 containing construct and/or control consteucts. After 24-48 h incubation in humidified CO2 incubator, cultures were fixed in 3\% formaldehyde solution and visualized by a light microscope. $\mathbf{a}$, b DU145 cells migration as a negative control. c, d migration of DU145 cells which had been treated by CM from pAAV-MCS-GFP / control cultures. e, $\mathbf{f}$ migration in DU145 cultures which had been treated by CM from pAAV-sFLT01-HisTag-GFP transfected cultures. $\mathbf{g}$ data indicates that following treatment with sFLT01 protein containing CM for $24 \mathrm{~h}$ and $48 \mathrm{~h}$, the mobility of DU145 cells was significantly decreased versus the control group (treated by CM from pAAV-MCS-GFP transfected cells); 0.43-fold $(P<0.05)$ versus 2.27 -fold $(P<0.001)$

Recent studies demonstrated that low glucose, hypoxia, and acidosis conditions in tumoral microenvironment could activate unfolded protein reaction and trigger GRP78 expression [38, 39]. In a hypoxic microenvironment, it has been suggested that GRP78 may be a downstream target of the HIF-1a gene. Anti-angiogenic molecules by reducing cell proliferation, hypoxia, and its involved factor (HIF-1a), lead to a decrease in the expression of GRP78 protein [40]. XBP-1-HIF-1a complex represents a crucial role in tumor growth and relapse by regulating genes involved in angiogenesis and metabolism such as VEGF, glucose transporter 1 (GLUT1), or pyruvate dehydrogenase kinase 1 (PDK1). Hypoxia leads to activation of angiogenic signaling pathways through production of the best-characterized pro-angiogenic factor
VEGFA165 (VEGF). It has been shown that all three transcription factors of the UPR signaling pathway (spliced XBP-1, ATF4, and cleaved ATF6) have binding sites on the VEGF promoter region and enhance its transcription [38, 41, 42]. Considering reported experimental evidences in strong association between GRP78 and hypoxia as well as the anti-angiogenic properties of the sFLT01 molecule, it can be concluded that the sFLT01 molecule could inhibit the ER stress in a disease condition as like as tumor microenvironment which is suffering from severe hypoxia.

According to our data, sFLT01 protein showed modulatory impact on proliferation, invasion, and migration of DU145 cells along with the potential of HUVECs angiogenesis. Real-Time PCR analysis depicted a significant downregulation in GRP78, MMP2 and MMP9 


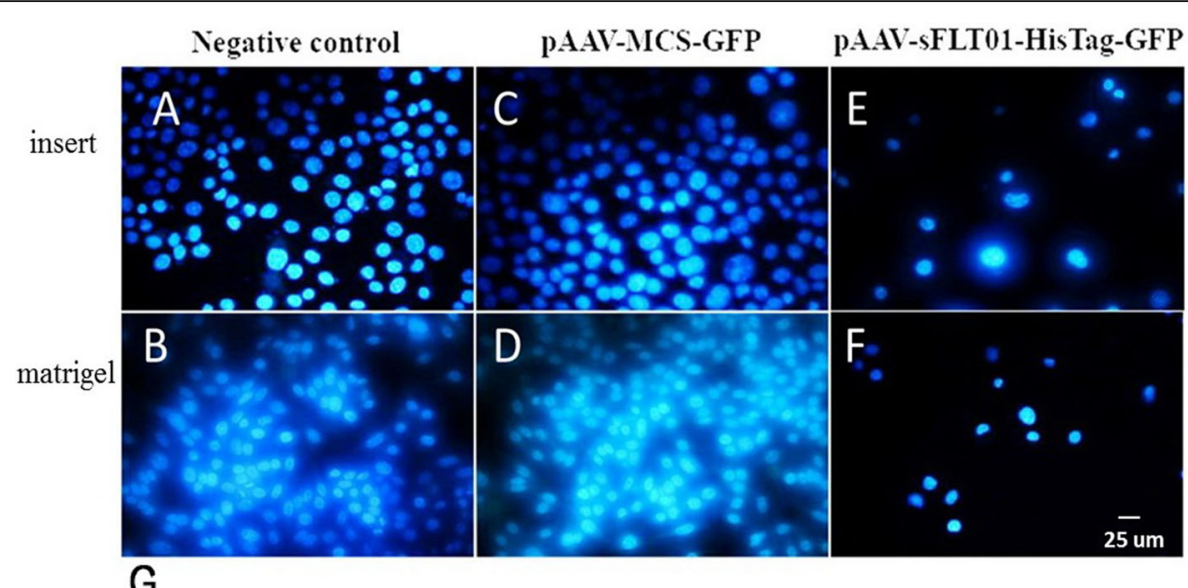

G

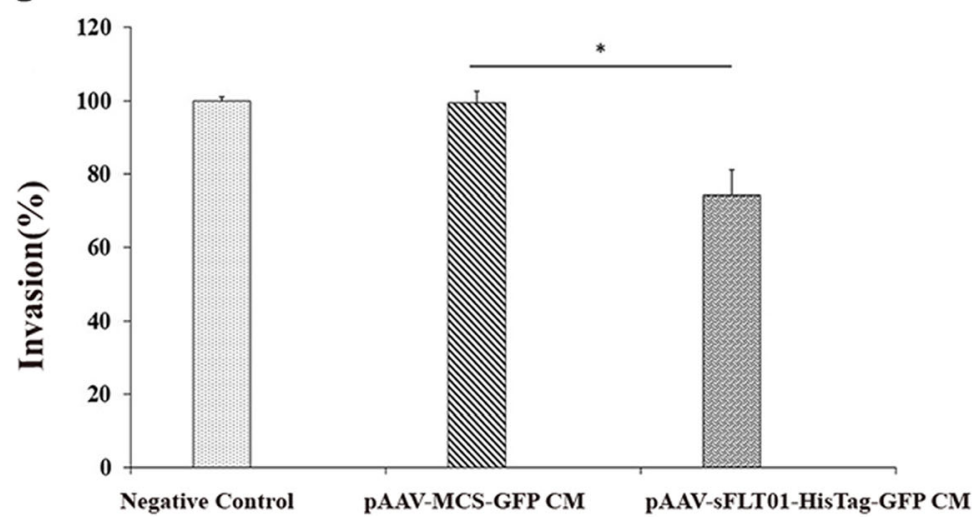

Fig. 5 Cell invasion assay. DU145 cells were seeded in matrigel-coated transwell chambers. $5 \times 10^{5}$ DU145 cells were transfected by pAAV-sFLT01HisTag-GFP and/or control (PAAV-MCS-GFP transfected DU145 cells). Serum-free media was prepared and added to the matrigel-coated transwell chambers. The chambers were then placed in the lower plate which had been filled with 10\% FBS containing media, After $24 \mathrm{~h}$ the non-invading cells were removed, membranes were fixed in methanol, and stained with DAPI. a Dapi staning of DU145 cells on insert (without matrigel), (B) Dapi staning of DU145 cells on insert coated with matrigel. c Dapi staning of DU145 cells which had been transfected by pAAV-MCS-GFP, as a control. d Dapi staning of DU145 cells which had been transfected by PAAV-MCS-GFP, on insert coated by matrigel as control. e Dapi staning of DU145 cells which had been transfected by PAAV-sFLT01-HisTag-GFP, on insert. $\mathbf{f}$ Dapi staning of DU145 cells which had been transfected by pAAV-sFLT01-HisTag-GFP, on insert coated matrigel. Data showed that sFLT01 inhibited invasiveness of DU145 cells compared to control. $\mathbf{g}$ Each value is the mean \pm SD of three independent experiments. The asterisks indicate significantly different from the control group

transcripts' levels, and a subsequent elevation of TIMP1 and TIMP2 expression under sFLT01 stimulation was detected. Moreover, there are some reports on the inhibitory effects of anti-VEGF drugs on ER stress indicators at hypoxic conditions in retinal pigmented epithelium cells (RPE) as well. Bevacizumab mitigated ER stress in human RPE cells cultured under hypoxic conditions. It reduced expression of two ER stress indicators, GRP78 and CHOP, under hypoxic conditions [43].

\section{Conclusion}

As prescribed studies highlighted the critical role of GRP78 in PC development, the current investigation was made to study whether the anticancer impact of sFLT01 chimeric receptor could be mediated through suppressing the VEGF/GRP78 axis.
Our data showed that sFLT01 treatment also had a positive impact on TIMP1\&2 expression. TIMPs as the known negative regulators of MMPs highly implicated in cancer malignancies $[44,45]$. At the protein level, TIMPs could be targeted by multiple inhibitors, including GRP78, which has been shown to bind to TIMPs directly and forms GRP78-TIMP complex [45]. Accordingly, GRP78 inhibition with the Indolylkojyl methane analog IKM5 was recently reported to prevent GRP78-TIMP complex formation and abrogated invasiveness in breast cancer cells [46]. On the other hand, the expression level of TIMP1 in cancer cells treated with IKM5 was significantly higher than the control group, which is in line with our observations. Although the exact underlined mechanism remains unknown, one might speculate that TIMPs upregulation in cancer cells treated with GRP78 inhibitors might be mediated through transforming 


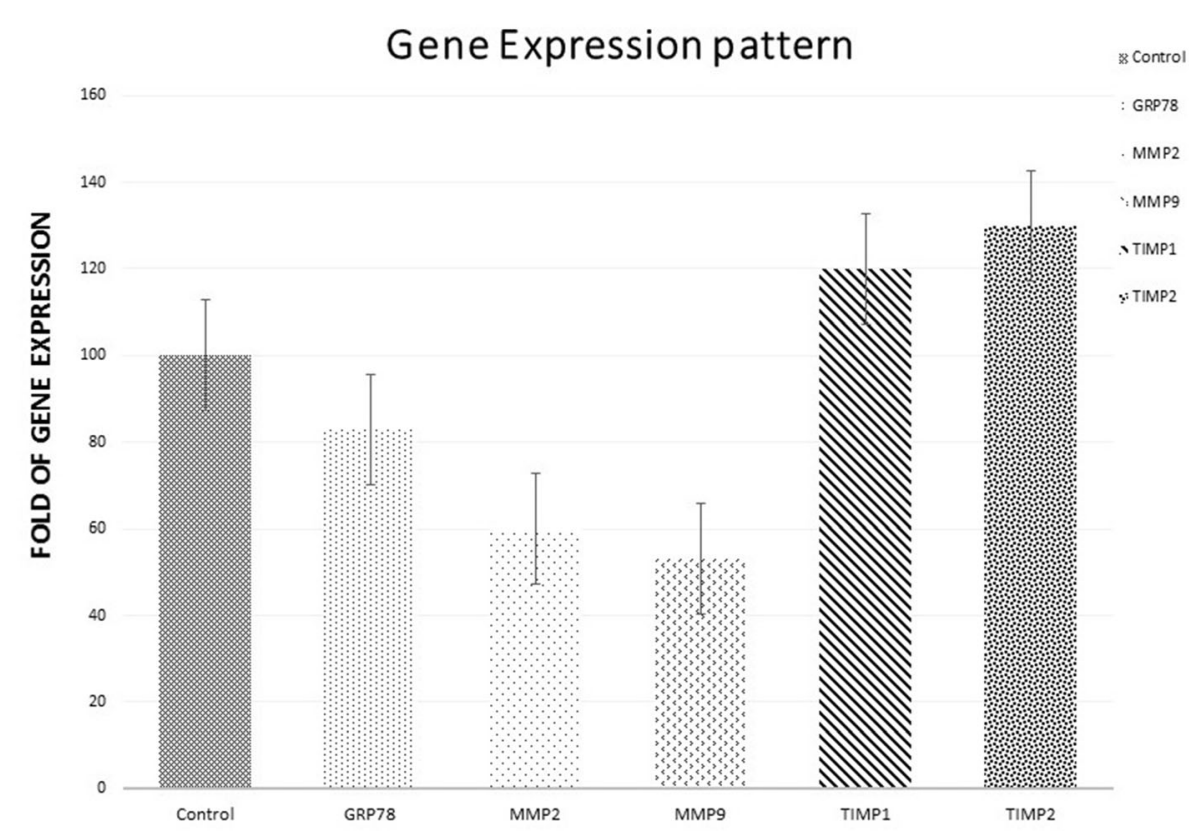

Fig. 6 Expression of selected genes. mRNA levels of the interested genes were measured and adjusted to GAPDH $36 \mathrm{~h}$ after transfection. Data showed that in sFLT01 treated DU145 cultures GRP78, MMP2, and MMP9 decreased about 17, 40, and 43\%, respectively. However, TIMP1 (20\%) and TIMP2 (30\%) revealed increased expression in treated cultures

growth factor- $\beta$ (TGF- $\beta$ ) stimulation, as recently reported by Cultrara et al. [11].

In summary, this study highlighted some anticancer aspects of sFLT01 as a next-generation antiangiogenic agent and showed that the inhibitory impact of sFLT01 on angiogenesis, growth, invasiveness, and migration of cancer cells could be mediated through the modulation of VEGF/GRP78/MMP2\&9 axis and activation of TIMPs. For the first time, we demonstrated that sFLT01 protein is a novel therapeutic opportunity to suppress prostate tumor cells invasiveness.

However, more investigations are needed to elucidate the mechanism underlining sFLT01 anticancer activity.

\section{Materials and methods}

\section{Cell culture}

Human PC cell line DU145 along with the human embryonic kidneys (HEK293T) which were purchased from the National Institute of Genetic Engineering and Biotechnology cell bank (NIGEB Tehran, Iran) were considered for in vitro examinations. We used Roswell Park Memorial Institute (RPMI1640, Invitrogen, USA) and Dulbecco's Modified Eagle Medium (DMEM, Gibco, USA) for culturing DU145 and HEK293T cells, respectively. Each media was supplemented with 100,000 U/L of penicillin, $100 \mu \mathrm{g} / \mathrm{ml}$ streptomycin (Fluka, Switzerland), and $10 \%$ fetal bovine serum (FBS, Biowest, France). Cells incubation was carried out in a humidified 5\% CO2 incubator at $37^{\circ} \mathrm{C}$ (Binder, USA).

\section{Vector construct and transfection}

Human sFLT01 coding Sequence [21] was synthesized and His Tag sequence was added to the end of the construct with PCR reaction (primer sequences: $5^{\prime}$ - GAAT TCATGGTCAGCTACTG - 3' (Forward), and 5' - GGAT CCTCAGTGGTGGTGGTGGTGGTGTTTACCCGGAG ACAGGGAG - 3' (Reverse)). PCR product was cloned into pJET1.2/blunt plasmid (Thermo Fisher Scientific, Canada). The thermocycler was programmed as follows; $95^{\circ} \mathrm{C}$ for 5 min denaturation step, and 35 cycles consisted of $95^{\circ} \mathrm{C}$ for $30 \mathrm{~s}, 58^{\circ} \mathrm{C}$ for $30 \mathrm{~s}$, and $72^{\circ} \mathrm{C}$ for $2 \mathrm{~min}$ following an additional $72^{\circ} \mathrm{C}$ for $5 \mathrm{~min}$, final extension step with Pfu DNA Polymerase (Agilent, USA).

PCR product was inserted into a pJET1.2/blunt plasmid (Thermo Fisher Scientific, Canada) and cloned in Escherichia coli XL10 bacteria (Agilent, USA) using the heat-shocked method [11]. After bacterial proliferation, the pJET-sFLT01-HisTag plasmids were extracted with the Plasmid Extraction Kit (SinaClon Co, Iran) according to the company protocol. After recovering the sFLT01HisTag fragment from the gel, the fragment of interest was inserted into the pAAV-MCS-GFP vector (Agilent, USA) through a ligation protocol, and then the resulted plasmids were transformed into the host bacterial cells. Eventually, pAAV-sFLT01-HisTag-GFP plasmids were purified then analyzed with the gel electrophoresis method and sequences were determined.

Human PC cell line DU145 was considered as the host for transfection of pAAV-sFLT01-HisTag-GFP and 
pAAV-MCS-GFP vectors. $4 \times 10^{6}$ cells seeded into each well of the six-well plates. Transfection was mediated by using the Lipofectamine 2000 reagent (Invitrogen, USA) according to the manufacturer's guidelines. In brief, $5 \mu \mathrm{g}$ of DNA sample was mixed with $525 \mu$ of the antibioticfree culture medium and added to a mixture of $21 \mu \mathrm{l}$ lipofectamine 2000 reagent in $502 \mu \mathrm{l}$ of culture medium. Following $20 \mathrm{~min}$ incubation at room temperature, the transfection mixture was gently dropped on the cells, admixed, and kept for $6 \mathrm{~h}$ at $37^{\circ} \mathrm{C}$ under $5 \% \mathrm{CO}_{2}$. After replacing the culturing medium, cells were incubated for the next $72 \mathrm{~h}$.

\section{RNA isolation and real-time PCR analysis}

Total RNA was isolated from DU145 treated and control cultures (DU145 cells transfected by pAAV-sFLT01HisTag-GFP or control vector, pAAV-MCS-GFP) using the TriPure Isolation Reagent (Roche, Germany), according to the manufacturer's protocol. The RNA samples were subsequently treated with $1 \mu \mathrm{g}$ DNase I enzyme (Accurate genomic DNA removal kit, ABMgood, Canada) for $1 \mathrm{~h}$ and quantified with an ND-1000 Nanodrop (Nanodrop Technologies, USA).

$1 \mu \mathrm{g}$ of total RNA was applied for cDNA synthesis by the QuantiTect Reverse Transcription Kit (Qiagen Inc., USA). Real time-PCR was carried out on a 7500 RealTime PCR System (Applied Biosystems, USA) with the QuantiFast SYBR Green PCR Kit (Qiagen Inc., USA). The thermocycler was programmed as follows; a $95^{\circ} \mathrm{C}$ for $3 \mathrm{~min}$ denaturation step, and 40 cycles consisted of $95^{\circ} \mathrm{C}$ for $10 \mathrm{~s}$ and $60^{\circ} \mathrm{C}$ for $30 \mathrm{~s}$. The expression level of sFLT01 was normalized to GAPDH as an endogenous control and the expression level of interested genes was calculated by using the $2^{-\Delta \Delta C T}$ method based on the threshold cycle $(\mathrm{Ct})$ values. Each sample was assessed in duplicate at least. The primer sequences were as follows: sFLT01 Forward 5' -AGGAAGGGAGCTCGTCATTC-3' and Reverse 5'-GCCCATTGACTGTTGCTTCA-3', GRP78 Forward 5' - CGTGGAGATCATCGCCAAC-3' and Reverse 5' -ACATAGGACGGCGTGATGC-3', MMP2 Forward 5'-TTGATGGCATCGCTCAGATC-3' and Reverse 5' ${ }^{\prime}$-TTGTCACGTGGCGTCACAGT-3', MMP9 Forward 5' - GTGATTGACGACGCCTTT - 3' and Reverse 5'- CAACTCGTCATCGTCG-3', TIMP1 Forward 5'- CTTCTGGCATCCTGTTGT-3' and Reverse 5' - ACTGCAGGTAGTGATGTG-3', TIMP2 Forward 5'-AAGCGGTCAGTGAGAAGGAAG-3' and Reverse 5' - GGGGCCGTGTAGATAAACTCTAT-3', and GAPDH Forward 5' -ACAGTCAGCCGCATCTTC3' and Reverse 5' - CTCCGACCTTCACCTTCC-3'.

\section{Purification and evaluation of sFLT01 protein}

To determine the sFLT01 protein concentration in transfected HEK293T cells. Culture medium was collected $72 \mathrm{~h}$ after transfection and centrifuged for 10 min at $500 \times g$ to remove the bulk of cell debris. Histagged sFLT01 protein was purified using the nickel affinity chromatography (Ni-NTA agarose beads, ABT, Spain), according to the company protocols. Next, SDSPAGE and Western blotting techniques were applied to determine the level of sFLT01 protein using 1:50000 human VEGFR1/Flt-1 primary antibody and a 1:100000 goat IgG HRP-conjugated secondary antibody (R\&D Systems, USA). Blots were developed with using ECL select ${ }^{\text {tw }}$ Western blotting detection reagent (GE Healthcare, Amersham $^{\text {six }}$,Buckinghamshire HP7 9NA UK) and a specific band was visualized.

\section{Cellular viability assay (MTT)}

Viability of cell cultures was determined by the MTT colorimetric assay (Sigma-Aldrich, USA). A total of $6.6 \times 10^{3}$ DU145 cells/well were seeded into each well of a 96-well plate and incubated with $100 \mu$ media containing RPMI1640 and DU145 cells conditioned medium in a ratio of 2:1 (DU145 cells transfected by pAAVsFLT01-HisTag-GFP or control pAAV-MCS-GFP transfected DU145 cells), for $48 \mathrm{~h}$ at $37^{\circ} \mathrm{C}$ under $5 \% \mathrm{CO}_{2}$. Then, each well-received $20 \mu \mathrm{l}$ of MTT $(0.5 \mathrm{mg} / \mathrm{ml}$ in PBS, $\mathrm{pH}$ 7.2) and cultures were kept for the next $4 \mathrm{~h}$. After removing the solution, cells were treated with $200 \mu \mathrm{l}$ of dimethyl sulfoxide (DMSO, Sigma-Aldrich, USA) for $5 \mathrm{~min}$. The number of viable cells was assessed using an ELx800 absorbance microplate reader (Bio-Rad, USA), at a wavelength of $580 \mathrm{~nm}$.

\section{Tube formation assay}

Tube formation assay was performed to determine the ability of sFLT01 to inhibit tube formation in the human umbilical vein endothelial cells (HUVECs). The 96-well plates were coated with growth factor-reduced Matrigel (BD Bioscience, Belgium), then HUVECs $\left(3.5 \times 10^{4}\right.$ cells/ well) seeded on top of Matrigel-coated wells. After $24 \mathrm{~h}$, collected CMs from DU145 cells transfected by pAAVsFLT01-HisTag-GFP or control, pAAV-MCS-GFP containing construct (supplemented with 10\% FBS) were added and incubated for $18 \mathrm{~h}$. To compare tube formation ability of groups, the number of master junctions along with the number of meshes from four randomly picked spots were evaluated under an inverted phasecontrast microscope (Olympus, Japan) and quantified with ImageJ software (AngioTool plugin).

\section{Wound healing assay and cell invasion assay}

To investigate the impact of sFLT01 on cancer cells migration, DU145 cells were seeded in a six-well plate at a density of $2 \times 10^{5}$ per well, and cultured for $24 \mathrm{~h}$. When cultures developed to a near monolayer, a wound was made using the tip of a pipette and cells were treated 
with CM (from treated DU145 transfected by pAAVsFLT01-HisTag-GFP or control which transected by pAAV-MCS-GFP). Following $24-48 \mathrm{~h}$ incubation, cells were fixed in a $3 \%$ formaldehyde solution for $15 \mathrm{~min}$ and imaged using different fields. The relative migration rates of DU145 cells were determined by dividing the migration distance by the time.

Invasion analysis was performed by using matrigel (BD Biosciences, San Jose, CA, USA) was added to the underside of each insert and left for $16 \mathrm{~h}$ at $37^{\circ} \mathrm{C}$ in a $5 \%$ CO $2 \mathrm{~atm}$. According to the manufacturer's instruction. First, a mixture of $5 \times 10^{5}$ DU145 cells transfected by pAAV-sFLT01-HisTag-GFP or, control, pAAV-MCSGFP transfected DU145 cells and serum-free media was prepared and added to the matrigel-coated transwell chambers (Nunc, Roskilde, Denmark) with $8.0 \mu \mathrm{m}$ diameter pores. The chambers were then placed in the lower plate filled with $10 \%$ FBS containing media and maintained for $24 \mathrm{~h}$ at $37{ }^{\circ} \mathrm{C}$ under $5 \% \mathrm{CO}_{2}$. After removing the non-invading cells, the cells were fixed in the chilled methanol for $20 \mathrm{~min}$ at $-20^{\circ} \mathrm{C}$. The plate was rewashed with the PBS buffer twice and stained with DAPI for the next $3 \mathrm{~min}$. Cell analysis was carried out using a fluorescent microscope (Carl Zeiss, Germany).

\section{Acknowledgments}

This work was supported by National Institute of Genetic Engineering and Biotechnology (NIGEB) through grant no.600. We wish to acknowledge staff of Blood Transfusion Research Center for contribution to this work. Our gratitude thanks to INSF, Iran National Science Foundation, for Doctoral Research Support Grant to perform this study (No. 96004188).

\section{Authors' contributions \\ Sepideh Taghizadeh performed research, analyzed data, and wrote the manuscript. Zahra-Soheila Soheili designed research, edited the manuscript, provided the budget, and supervised the study. Mehdi Sadeghi participated in the design of experiments. Shahram Samiei performed the experiments. Ehsan Ranaei Pirmardan participated in the design of experiments and edi- ted the manuscript. Ali Kashanian performed the experiments; participated in the design of experiments, research, and data analysis. Fahimeh Zakeri per- formed the experiments. Hamid Latifi-Navid participated in the design of ex- periments and edited the manuscript. Hoda Shams Najafabadi participated in the design of experiments and data analysis. The authors read and ap- proved the final manuscript.}

\section{Funding}

Grant no.600 and Iran National Science Foundation (INSF), Iran National Science Foundation, for Doctoral Research Support Grant to perform this study (No. 96004188).

\section{Availability of data and materials}

The data that support the findings of this study are available on request from the corresponding author. The data are not publicly available due to privacy or ethical restrictions.

\section{Declarations}

\section{Ethics approval and consent to participate}

All protocols to use the Human Prostate Cancer Cell lines were reviewed and confirmed by Ethics committee of National Institute of Genetic Engineering and Biotechnology (NIGEB). Consent to participate-NA/Not applicable.

\section{Consent for publication}

Not applicable.

\section{Competing interests}

There was no competing financial interests exist in this project.

\section{Author details}

'Department of Molecular Medicine, National Institute of Genetic Engineering and Biotechnology, 14965/161, Tehran, Iran. ${ }^{2}$ Blood Transfusion Research Center, High Institute for Research and Education in Transfusion Medicine, Tehran, Iran. ${ }^{3}$ Molecular Biomarkers Nano-Imaging Laboratory, Brigham and Women's Hospital, Department of Radiology Harvard Medical School, Boston, MA, USA.

Received: 30 January 2021 Accepted: 20 April 2021

Published online: 19 May 2021

\section{References}

1. Siegel RL, Miller KD, Jemal A. Cancer statistics, 2019. CA Cancer J Clin. 2019; 69(1):7-34.

2. Xie T, Dong B, Yan Y, Hu G, Xu Y. Association between MMP-2 expression and prostate cancer: a meta-analysis. Biomed Rep. 2016;4(2):241-5. https:// doi.org/10.3892/br.2015.553.

3. Gundem G, Van Loo P, Kremeyer B, Alexandrov LB, Tubio JM, Papaemmanuil $\mathrm{E}$, et al. The evolutionary history of lethal metastatic prostate cancer. Nature. 2015;520(7547):353-7. https://doi.org/10.1038/nature14347.

4. Thakur MK, Heilbrun L, Dobson K, Boerner J, Stark K, Li J, et al. Phase I trial of the combination of docetaxel, prednisone, and pasireotide in metastatic castrate-resistant prostate cancer. Clin Genitourinary Cancer. 2018;16(3): e695-703. https://doi.org/10.1016/j.clgc.2018.01.019.

5. Belderbos BP, Hussaarts KG, van Harten LJ, Oomen-de Hoop E, de Bruijn P, Hamberg P, et al. Effects of prednisone on docetaxel pharmacokinetics in men with metastatic prostate cancer: a randomized drug-drug interaction study. Br J Clin Pharmacol. 2019;85(5):986-92. https://doi.org/10.1111/bcp.13889.

6. Langer R, Feith M, Siewert JR, Wester HJ, Hoefler H. Expression and clinical significance of glucose regulated proteins GRP78 (BiP) and GRP94 (GP96) in human adenocarcinomas of the esophagus. BMC Cancer. 2008;8(1):70. https://doi.org/10.1186/1471-2407-8-70.

7. Chen J, De S, Brainard J, Byzova TV. Metastatic properties of prostate Cancer cells are controlled by VEGF. Cell Commun Adhes. 2009;11(1):1-11.

8. Huang L-W. Overexpression of GRP78 Is Associated With Malignant Transformation in Epithelial Ovarian Tumors<huang2012.pdf>; 2012

9. Lee AS. GRP78 induction in cancer: therapeutic and prognostic implications. Cancer Res. 2007;67(8):3496-9. https://doi.org/10.1158/00085472.CAN-07-0325.

10. Fu Y, Lee AS. Glucose regulated proteins in cancer progression, drug resistance and immunotherapy. Cancer Biol Ther. 2006;5(7):741-4. https:// doi.org/10.4161/cbt.5.7.2970.

11. Cultrara CN, Kozuch SD, Ramasundaram P, Heller CJ, Shah S, Beck AE, et al. GRP78 modulates cell adhesion markers in prostate Cancer and multiple myeloma cell lines. BMC Cancer. 2018;18(1):1263. https://doi.org/10.1186/s12 885-018-5178-8.

12. Fukushima R, Kasamatsu A, Nakashima D, Higo M, Fushimi K, Kasama H, et al. Overexpression of translocation associated membrane protein 2 leading to Cancer-associated matrix metalloproteinase activation as a putative metastatic factor for human Oral Cancer. J Cancer. 2018;9(18):332633. https://doi.org/10.7150/jca.25666.

13. Li H, Song H, Luo J, Liang J, Zhao S, Su R. Knockdown of glucose-regulated protein 78 decreases the invasion, metalloproteinase expression and ECM degradation in hepatocellular carcinoma cells. J Exp Clin Cancer Res. 2012; 31(1):39. https://doi.org/10.1186/1756-9966-31-39.

14. Xiao L-J, Lin P, Lin F, Liu X, Qin W, Zou H-F, et al. ADAM17 targets MMP-2 and MMP-9 via EGFR-MEK-ERK pathway activation to promote prostate cancer cell invasion. Int J Oncol. 2012;40(5):1714-24. https://doi.org/10.3892/ ijo.2011.1320.

15. Yu E-M, Jain M, Aragon-Ching JB. Angiogenesis inhibitors in prostate cancer therapy. Discov Med. 2010;10(55):521-30.

16. Bilusic M, Wong Y-N. Anti-angiogenesis in prostate cancer: knocked down but not out. Asian J Androl. 2014;16(3):372-7. https://doi.org/10.4103/1008682X.125903.

17. Bagley RG, Kurtzberg L, Weber W, Nguyen T-H, Roth S, Krumbholz R, et al. SFLT01: a novel fusion protein with antiangiogenic activity. Mol Cancer Ther. 2011;10(3):404-15. https://doi.org/10.1158/1535-7163.MCT-10-0813. 
18. Maclachlan TK, Lukason M, Collins M, Munger R, Isenberger E, Rogers C, et al. Preclinical safety evaluation of AAV2-sFLT01- a gene therapy for agerelated macular degeneration. Mol Ther. 2011;19(2):326-34. https://doi.org/1 $0.1038 / \mathrm{mt} .2010 .258$

19. Gupta SC, Kim JH, Prasad S, Aggarwal BB. Regulation of survival, proliferation, invasion, angiogenesis, and metastasis of tumor cells through modulation of inflammatory pathways by nutraceuticals. Cancer Metastasis Rev. 2010;29(3):405-34. https://doi.org/10.1007/s10555-010-9235-2.

20. de Brot S. Regulation of vascular endothelial growth factor (VEGF) in prostate cancer; 2015.

21. Pechan $P$, Rubin H, Lukason M, Ardinger J, DuFresne E, Hauswirth WW, et al. Novel anti-VEGF chimeric molecules delivered by AAV vectors for inhibition of retinal neovascularization. Gene Ther. 2009;16(1):10-6. https://doi.org/10.1 038/gt.2008.115

22. Liu L, Yu H, Huang X, Tan H, Li S, Luo Y, et al. A novel engineered VEGF blocker with an excellent pharmacokinetic profile and robust anti-tumor activity. BMC Cancer. 2015;15(1):170. https://doi.org/10.1186/s12885-015-1140-1.

23. Zhang L, Chen Y, Li F, Bao L, Liu W. Atezolizumab and Bevacizumab attenuate Cisplatin resistant ovarian Cancer cells progression synergistically via suppressing epithelial-Mesenchymal transition. Front Immunol. 2019;10: 867. https://doi.org/10.3389/fimmu.2019.00867.

24. Fang J, Ding $M$, Yang $L$, Liu LZ, Jiang BH. PI3K/PTEN/AKT signaling regulates prostate tumor angiogenesis. Cell Signal. 2007;19(12):2487-97. https://doi. org/10.1016/j.cellsig.2007.07.025.

25. Kumar P, Coltas IK, Kumar B, Chepeha DB, Bradford CR, Polverini PJ. BCl-2 protects endothelial cells against gamma-radiation via a Raf-MEK-ERKsurvivin signaling pathway that is independent of cytochrome $c$ release. Cancer Res. 2007;67(3):1193-202. https://doi.org/10.1158/0008-5472.CAN06-2265.

26. Degirmenci U, Wang M, Hu J. Targeting Aberrant RAS/RAF/MEK/ERK Signaling for Cancer Therapy. Cells. 2020;9:1

27. Lugano R, Ramachandran M, Dimberg A. Tumor angiogenesis: causes, consequences, challenges and opportunities. Cell Mol Life Sci. 2019;77:1745.

28. Pratheeshkumar $\mathrm{P}$, Son YO, Budhraja A, Wang X, Ding S, Wang L, et al. Luteolin inhibits human prostate tumor growth by suppressing vascular endothelial growth factor receptor 2-mediated angiogenesis. PLoS One 2012;7(12):e52279. https://doi.org/10.1371/journal.pone.0052279.

29. Huveldt D, Lewis-Tuffin $\amalg$, Carlson BL, Schroeder MA, Rodriguez F, Giannini C, et al. Targeting Src family kinases inhibits bevacizumab-induced glioma cell invasion. PLoS One. 2013;8(2):e56505. https://doi.org/10.1371/journal. pone.0056505

30. Huang M, Huang B, Li G, Zeng S. Apatinib affect VEGF-mediated cell proliferation, migration, invasion via blocking VEGFR2/RAF/MEK/ERK and PI3K/AKT pathways in cholangiocarcinoma cell. BMC Gastroenterol. 2018 18(1):169. https://doi.org/10.1186/s12876-018-0870-3.

31. Lamalice L, Le Boeuf F, Huot J. Endothelial cell migration during angiogenesis. Circ Res. 2007;100(6):782-94. https://doi.org/10.1161/01.RES. 0000259593.07661.1e.

32. Katanasaka $Y$, Ishii T, Asai T, Naitou H, Maeda N, Koizumi F, et al. Cancer antineovascular therapy with liposome drug delivery systems targeted to BiP/GRP78. Int J Cancer. 2010;127(11):2685-98. https://doi. org/10.1002/ijc.25276.

33. Dong D, Ni M, Li J, Xiong S, Ye W, Virrey JJ, et al. Critical role of the stress chaperone GRP78/BiP in tumor proliferation, survival, and tumor angiogenesis in transgene-induced mammary tumor development. Cancer Res. 2008;68(2):498-505. https://doi.org/10.1158/0008-5472.CAN-07-2950.

34. Dong D, Stapleton C, Luo B, Xiong S, Ye W, Zhang Y, et al. A critical role for GRP78/BiP in the tumor microenvironment for neovascularization during tumor growth and metastasis. Cancer Res. 2011;71(8):2848-57. https://doi. org/10.1158/0008-5472.CAN-10-3151.

35. Niu Z, Wang M, Zhou L, Yao L, Liao Q, Zhao Y. Elevated GRP78 expression is associated with poor prognosis in patients with pancreatic cancer. Sci Rep. 2015:5(1):16067. https://doi.org/10.1038/srep16067.

36. Guo K, Ma Q, Li J, Wang Z, Shan T, Li W, et al. Interaction of the sympathetic nerve with pancreatic cancer cells promotes perineural invasion through the activation of STAT3 signaling. Mol Cancer Ther. 2013; 12(3):264-73. https://doi.org/10.1158/1535-7163.MCT-12-0809.

37. dong Li H, Huang C, jian Huang $K$, dong Wu W, Jiang T, Cao J, et al. STAT3 knockdown reduces pancreatic cancer cell invasiveness and matrix metalloproteinase-7 expression in nude mice. PLoS One. 2011;6(10):e25941.
38. Binet F, Sapieha P. ER Stress and Angiogenesis. Cell Metab. 2015;22(4):56075. https://doi.org/10.1016/j.cmet.2015.07.010.

39. Bartoszewska S, Collawn JF. Unfolded protein response (UPR) integrated signaling networks determine cell fate during hypoxia. Cell Mol Biol Lett. 2020;25(1):18. https://doi.org/10.1186/s11658-020-00212-1.

40. Cai H, Gong L, Liu J, Zhou Q, Zheng Z. Diosgenin inhibits tumor angiogenesis through regulating GRP78-mediated HIF-1alpha and VEGF/ VEGFR signaling pathways. Pharmazie. 2019;74(11):680-4. https://doi.org/1 0.1691/ph.2019/9526.

41. Pereira ER, Liao N, Neale GA, Hendershot LM. Transcriptional and posttranscriptional regulation of proangiogenic factors by the unfolded protein response. PLoS One. 2010;5:9.

42. Ghosh R, Lipson KL, Sargent KE, Mercurio AM, Hunt JS, Ron D, et al. Transcriptional regulation of VEGF-A by the unfolded protein response pathway. PLoS One. 2010;5(3):e9575. https://doi.org/10.1371/journal.pone. 0009575.

43. Chigusa S, Moroi T, Shoji Y. State-of-the-art calculation of the decay rate of electroweak vacuum in the standard model. Phys Rev Lett. 2017;119(21): 211801. https://doi.org/10.1103/PhysRevLett.119.211801.

44. Zhang S, Li L, Lin J-Y, Lin H. Imbalance between expression of matrix metalloproteinase- 9 and tissue inhibitor of metalloproteinase- 1 in invasiveness and metastasis of human gastric carcinoma. World Gastroenterol: WJG. 2003;9(5):899-904. https://doi.org/10.3748/wjg.v9.i5.899.

45. Lu H, Cao X, Zhang $H$, Sun G, Fan G, Chen $L$, et al. Imbalance between MMP-2, 9 and TIMP-1 promote the invasion and metastasis of renal cell carcinoma via SKP2 signaling pathways. Tumor Biol. 2014;35(10):9807-13. https://doi.org/10.1007/s13277-014-2256-7.

46. Nayak D, Katoch A, Sharma D, Faheem MM, Chakraborty S, Sahu PK, et al. Indolylkojyl methane analogue IKM5 potentially inhibits invasion of breast cancer cells via attenuation of GRP78. Breast Cancer Res Treat. 2019;177: 307-23.

\section{Publisher's Note}

Springer Nature remains neutral with regard to jurisdictional claims in published maps and institutional affiliations.
Ready to submit your research? Choose BMC and benefit from:

- fast, convenient online submission

- thorough peer review by experienced researchers in your field

- rapid publication on acceptance

- support for research data, including large and complex data types

- gold Open Access which fosters wider collaboration and increased citations

- maximum visibility for your research: over $100 \mathrm{M}$ website views per year

At BMC, research is always in progress.

Learn more biomedcentral.com/submissions 